\title{
Is the 3D transesophageal Doppler color echocardiogram better than 2D to measure single defects of the interatrial septum in the catheterization laboratory?
}

\section{¿El ecocardiograma transesofágico Doppler color 3D es mejor que el 2D para medir defectos únicos del tabique interauricular en la sala de hemodinamia?}

\author{
Alejandro E. Contreras ${ }^{1 *}$, Adolfo Ferrero-Guadagnoli ${ }^{2}$, Gabriela Vilte ${ }^{1}$, and Alejandro Peirone ${ }^{2}$ \\ ${ }^{1}$ Department of Cardiology and ${ }^{2}$ Catheterization Laboratory, Hospital Privado Universitario de Córdoba, Córdoba, Argentina
}

The relationship of atrial septal defect (ASD) with adjacent structures, the measuring of its dimensions, and the presence of adequate borders are essential variables when deciding the feasibility of proposing closure by catheterization'. Measurement of the defect with a balloon is a method that has been shown to be useful for the choice of the size of the device to be implanted, usually a device 1-2 $\mathrm{mm}$ larger than the waist size evoked by the balloon is selected ${ }^{2,3}$. As support and guide, at the catheterization laboratory, it is common for transesophageal echocardiography (TEE) to be used in its different modalities (two-dimensional 2D] - Three-dimensional 3D]). The purpose of our work was to determine whether the measurement of ASD by $3 D$ echo correlates better with the measurements with a balloon than those determined with $2 \mathrm{D}$ echo.

We conducted a retrospective study of patients who underwent percutaneous ASD closure between September 2015 and March 2018. We included the cases where 3D echo was used within the catheterization laboratory as imaging support. We correlated $3 \mathrm{D}$ echo and $2 \mathrm{D}$ echo measurement with the balloon measurement as the gold standard. We used Spearman's correlation test. A Bland and Altman gràph was plotted to assess the concordance betweenthe dimensions by 2D and 3D TEE. The SPSS 17 statistical package and MedCalc 18.11 were used.

We included 12 patients (7 males), with an average age of 16.1 years (5-70 years), and $40.8 \mathrm{~kg}$ weight $(18-110 \mathrm{~kg})$. Ten patients had single and two had multiple ASDs, $41.7 \%$ (5 patients) had deficient aortic rim and $16.7 \%$ (2 patients) had flaccid posterior rim. Ihe longest diameter measured by 2D TEE was 15.4 $\mathrm{mm}$ (9-31 mm), the longest diameter by 3D TEE was $14.9 \mathrm{~mm}(8-31 \mathrm{~mm})$, and the diameter measured by balloon was $17.7 \mathrm{~mm}(11-25 \mathrm{~mm})$. The inserted devices were $20.5 \mathrm{~mm}$ on average $(14-30 \mathrm{~mm})$. The correlation between 2D TEE and balloon was good $(r=0.88 ; p=0.001)$, and also between 3D TEE and balloon ( $r=0.83 ; p=0.001$ ), as well as the agreement between 2D and 3D TEE (Figs. 1 and 2).

$3 D$ TEE in the catheterization laboratory is highly useful for the assessment of multiple defects and residual defects closure ${ }^{4}$. Nearly $8 \%$ of ASDs of the
Date of reception: 15-06-2018 C.P. X5016KEH, Córdoba, Argentina E-mail: aletreras@ hotmail.com 2604-7063/@ 2019 Instituto Nacional de Cardiología Ignacio Chávez. Published by Permanyer. This is an open access article under the CC BY-NG-ND license (http://creativecommons.org/licenses/by-nc-nd/4.0/).
Available online: 06-05-2019 Arch Cardiol Mex (Eng). 2019;89(3):249-251 www.archivoscardiologia.com 

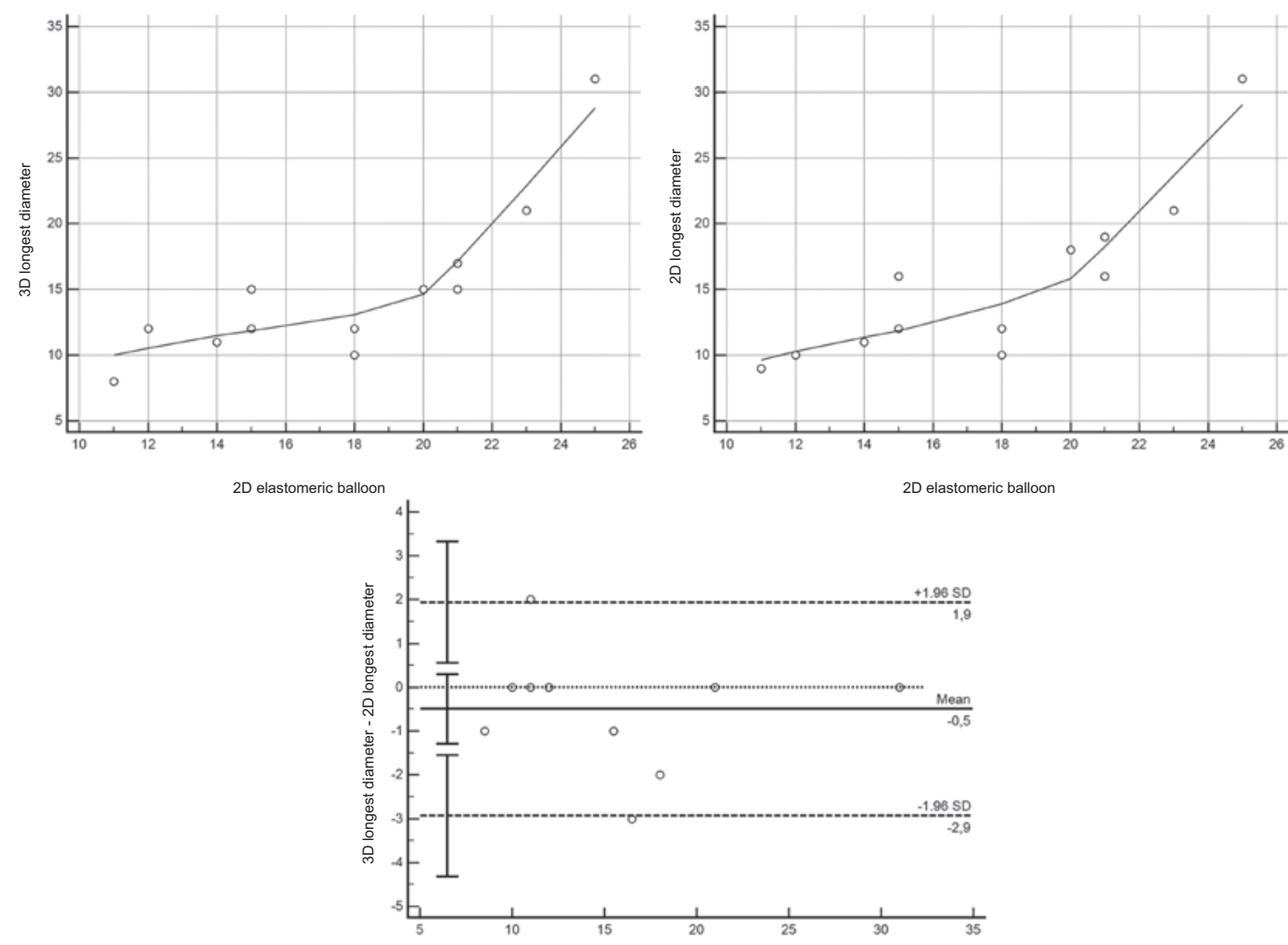

$3 \mathrm{D}$ longest diameter and 2D longest diameter mean

Figure 1. Correlation between $3 \mathrm{D}$ echo and balloon (left, $r=0.83$ ) and between $2 \mathrm{D}$ echo and balloon (center, $r=0.88$ ). Bland and Altman graph showing the concordance between longest diameter by 3D and 2D echo $(p=0.19)$.
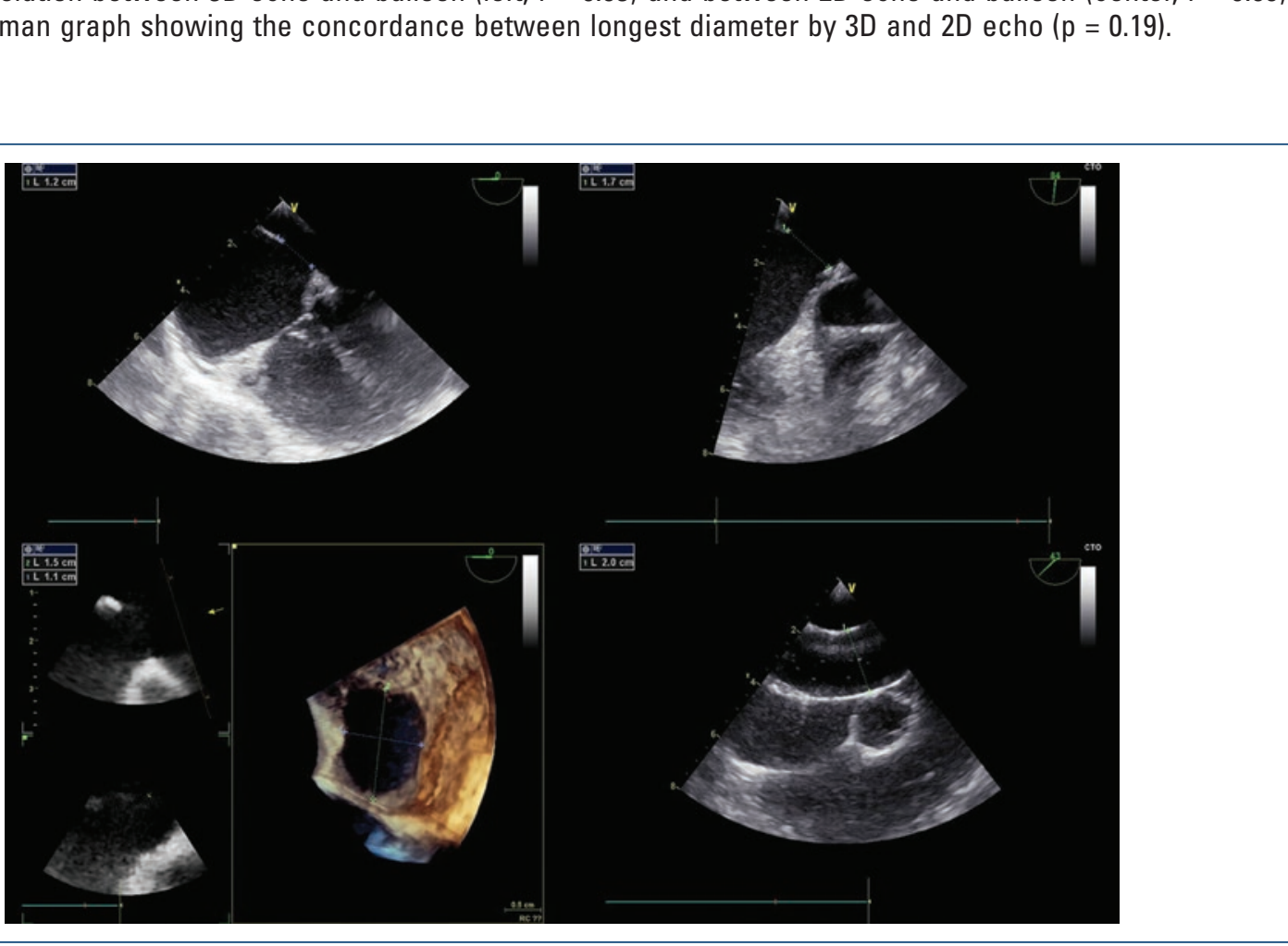

Figure 2. Measurement with two-dimensional transesophageal echocardiogram (upper left and right, 0 and 90 degrees, respectively). Measurement with three-dimensional transesophageal echocardiogram (bottom left). Measurement with balloon (bottom right). 
ostium secundum type are multiple ${ }^{5}$. 3D TEE-based formulas have been proposed for the choice of the size of the device to be implanted ${ }^{6}$, as well as 3D usefulness to avoid the use of the balloon for measuring the defect $^{7}$; however, no study has shown that $3 D$ TEE is clearly better in the measurement of single defects ${ }^{4,6,8}$. In our experience, both methods (2D and 3D TEE) had a good correlation with the measurement with balloon, but there were no differences between 2D and 3D TEE.

3D images are essential for the interventional cardiologist. They improve spatial orientation in some circumstances, for example, at the moment of MitraClip implantation or in the presence of interatrial septum multiple defects. The main disadvantage of $3 \mathrm{D}$ is the restriction in terms of the minimum patient weight required, since there are no pediatric probes, and its use is recommended for patients weighing more than $35 \mathrm{~kg}$, although, in our case, it could be used without complications in a patient of $18 \mathrm{~kg}$.

In most ASDs of the ostium secundum type, 2D TEE is the method of choice for control in the catheterization laboratory ${ }^{5}$, especially if the interatrial septum is not flaccid; conversely, if the defect is more complex, oval or multiple, 3D TEE can provide an advantage in anatomical assessment and for the choice of devices ${ }^{9}$.

\section{Conflicts of interest}

Doctors Contreras, Ferrero Guadagnoli, and Vilte have no conflicts of interest. Dr. Peirone is a Consultant and Proctor of PFM Medical, Proctor of St. Jude Medical, Proctor of Occlutech Medical, and Proctor of Cera Lifetech Science.

\section{Funding}

None.

\section{Ethical disclosures}

Protection of people and animal subjects. The authors declare that no experiments were performed on humans or animals for this study.

Confidentiality of data. The authors declare that they have followed the protocols of their work center on the publication of patient data.

Right to privacy and informed consent. GुThe authors have obtained written informed consent of the patients and/or subjects mentioned in the article. The corresponding author is in possession of athis document.

\section{References}

1. Mathewson JW, Bichell D, Rothman A, Ing FF. Absent posteroifferior and anterosuperior atrial septal defect rims: Factors affecting nonsürgical closure of large secundum defects using the Amplatzer occluder.d Am Soc Echocardiogr. 2004;17:62-9.

2. Du ZD, Cao Q, Rhodes J, Heitschmidt M, Hijazi ZM. Choice of size and results of transcatheter closure of atrial septal defect using the Amplatzer septal occluder. J Interv Cardiol. 2002;15:287-92.

3. Harper RW, Mottram PM, Mc Gaw DJ. Closure of secundum atrial septal defects with the Amplatzer septal occluder device: Techniques and problems. Catheter Cardiovasc Interv. 2002;57:508-24.

4. Simpson J, Lopez L, Acar P. Friedberg MK, Khoo NS, Ko HH, et al. Three dimensional echocardiography in congenital heart disease: An expert consensus document from the European Association of Cardiovascular Imaging and the American Society of Echcardiography. J Am Soc Echocardiogr. 2017;30:1-27.

5. Sobrino A, Basmadjian AJ, Ducharme A, Ibrahim R, MercieP $L A$, Pelletier $\mathrm{GB}$ et al. Ecocardiografía transesofagica multiplanar para la evaluación y el tratamiento percutáneo de la comunicación interaúricular tipo ostium secundum en el adulto. Arch Cardiol Mex. 2012;82:37-47.

6. Jang JY, Heo R, Cho MS, Bae J, Hong JA, Lee S, et al. Efficacy of 3D transoesophageal echocardiography for transcatheter device closure of atrial septal defect without ballon sizing. Eur Heart J Cardiovasc Imaging. 2018;19:684-9.

7. Hascoet S, Hadeed K, Marchal P, Dulac Y, Alacoque X, Heitz T, et al. The relation between atrial septal defect shape, diameter, and area using three-dimensional transoesophageal echocardiography and balloon sizing during percutaneous closure in children. Eur Heart J Cardiovasc Imaging. 2015;16:747-55.

8. Bhaya M, Mutluer FO, Mahan E, Mahan L, Hsiung MC, Yin WH, et al. Live/ real time three-dimensional transoesophageal echocardiography in percutaneous closure of atrial septal defects. Echocardiography. 2013;30:345-53.

9. Boon I, Vertongen K, Paelinck BP, Demulier L, Berendoncks AV, De Maeyer $\mathrm{C}$, et al. How to size ASDs for percutaneous closure. Pediatr Cardiol. 2018;39:168-75. 